\title{
Fertilidade do solo em pastagens no município de Vitória do Xingu, Pará, Brasil
}

\author{
Soil fertility in pastures in the municipality of Vitória do Xingu, Pará, Brazil \\ Fertilidad del suelo en pastos en el municipio de Vitória do Xingu, Pará, Brasil
}

\section{Resumo}

O município de Vitória do Xingu, no estado do Pará, apresentou rebanho bovino de cerca de 150 mil cabeças em 2019, evidenciando o potencial produtivo da região. Como subsídio para a expansão da atividade pecuária é necessário o desenvolvimento de estudos que visem à manutenção da qualidade do solo nos sistemas de produção, subsidiando alternativas de manejo. O objetivo do trabalho foi analisar os parâmetros físico-químicos do solo, considerando o período climático (chuvoso e seco) e a profundidade (0-20 e 20-40 cm), em uma propriedade particular, localizada no município de Vitória do Xingu, estado do Pará. Foram adotados três tratamentos, sendo T1 (vegetação secundária), T2 (pastagens de 10 anos) e T3 (pastagem de 30 anos). Para a análise estatística dos atributos foi utilizado o teste não-paramétrico de Wilcoxon $(\mathrm{P}<0,05)$. Todos os solos foram classificados com textura média. A densidade do solo foi maior em T3 e T2. A densidade de partículas foi maior em T1, seguido por T2 e T3. As áreas de pastagem apresentaram melhores condições de fertilidade que T1. O resultado do teste de Wilcoxon demonstrou que na camada superficial $(0-20 \mathrm{~cm})$, houve diferenças significativas entre os atributos analisados, sendo tais diferenças mais evidentes no período chuvoso. Os atributos diferiram na camada superficial de T1 em razão do período climático. O mesmo ocorreu com a camada subsuperficial de T3. A pastagem com 30 anos mostrou-se em maior estádio de degradação que as demais, sendo necessária a intervenção voltada para melhoria dos pastos, de modo a contribuir no potencial produtivo e de recuperação de pastagens na propriedade rural.

Palavras-chave: Fatores climáticos; Vegetação secundária; Profundidades; Atributos do solo.

\begin{abstract}
The municipality of Vitória do Xingu, in the State of Pará, presented a cattle herd of about 150 thousand heads in 2019, a consequence of the productive potential of the region. As a subsidy for the expansion of livestock activity, it is necessary to carry out studies aimed at maintaining soil quality in the systems established, subsidizing management alternatives. The objective of the work was to analyze the physical-chemical parameters considering the climatic period (rainy and dry) and the depth $(0-20$ and $20-40 \mathrm{~cm})$, in a private property, located in the Municipality of Vitória do Xingu, Pará, being T1 (secondary vegetation), T2 (pasture for 10 years) and T3 (pasture for 30 years). For the statistical analysis of the attributes, the Wilcoxon non-parametric test $(\mathrm{P}<0.05)$ was applied. All soils were classified
\end{abstract}


as medium texture. The soil density was higher in T3 and T2. The particle density was higher at T1, followed by T2 and T3. Pasture areas showed better fertility conditions than T1. The result of the Wilcoxon test demonstrated that in the superficial layer $(0-20 \mathrm{~cm})$, there were significant differences between the attributes analyzed, such differences being more evident in the rainy season. The attributes differed in the surface layer of T1 due to the climatic period. The same occurred with the T3 subsurface layer. The 30-year-old pasture proved to be in a greater stage of degradation than the others, requiring intervention aimed at improving pastures, in order to contribute to the productive and recovery potential of pastures on rural property.

Keywords: Climatic factors; Secondary vegetation; Depths; Soil attributes.

\section{Resumen}

El municipio de Vitória do Xingu, en el estado de Pará, presentó um rebaño de ganado de unas 150 mil cabezas en 2019, consecuencia del potencial productivo de la región. Como subsidio para la expansión de la actividad ganadera, és necesario realizar estudios dirigidos a mantener la calidad del suelo en los sistemas establecidos, subsidiando alternativas de manejo. El objetivo del trabajo fue analizar los parámetros físico-químicos considerando el período climático (lluvioso y seco) y la profundidad (0-20 y 20-40 cm), en una propiedad privada, ubicada en el Municipio de Vitória do Xingu, Pará, T1 (vegetación secundaria), T2 (pasto durante 10 años) y T3 (pasto durante 30 años). Para el análisis estadístico de los atributos se aplicó la prueba no paramétrica de Wilcoxon $(\mathrm{P}<0,05)$. Todos los suelos se clasificaron como de textura media. La densidad del suelo fue más grande en T3 y T2. La densidad de partículas fue más grande T1, seguida de T2 y T3. Las áreas de pasto mostraron mejores condiciones de fertilidad que T1. El resultado de la prueba de Wilcoxon demostró que em su capa superficial $(0-20 \mathrm{~cm})$, existían diferencias significativas entre los atributos analizados, siendo tales diferencias más evidentes en la época de lluvias. Los atributos diferían en la capa superficial de T1 debido al período climático. Lo mismo ocurrió con la capa del subsuelo T3. El apacentadero de 30 años resultó estar en una etapa de más grande degradación que las demás, requiriendo una intervención orientada a la mejora de los pastos, a fin de contribuir al potencial productivo y la recuperación de los pastos en la propiedad rural.

Palabras clave: Factores climáticos; Vegetación secundaria; Profundidades; Atributos del suelo.

\section{Introdução}

A atividade agropecuária está presente no Brasil desde a colonização portuguesa, com participação no desenvolvimento histórico de ocupação e no processo de formação territorial do país (Dias-Filho, 2019). A carne bovina produzida no país é, em sua maior parte, oriunda de sistemas a pasto, barateando os custos de produção. No entanto, apesar da importância econômica, o manejo inadequado do solo em áreas de pasto tem ocasionado o aumento da degradação dessas áreas, consequência principalmente de práticas como queimadas e superpastejo (Domingues \& Bermann, 2012).

Uma estimativa realizada por Dias et al. (2016) demostrou que no ano de 2012, 26\% da extensão territorial brasileira foi ocupada com agricultura, sendo $62 \%$ correspondido por pastagens e $38 \%$ ocupado com usos agrícolas. Cerca de $80 \%$ das áreas de pastagens são consideradas degradadas, sendo esta degradação relacionada à capacidade de suporte que é o indicador mais flexível para quantificar o estádio de degradação. Se por um lado é um dado preocupante, por outro, demonstra o potencial produtivo ainda existente no país quanto à produção animal.

Na região amazônica, essa atividade teve origem na década de 1960, o que estimulou rapidamente expansão a criação de bovinos em pastagens plantadas na região (Dias-Filho, 2019). O município de Vitória do Xingu, no Estado do Pará, apresentou o rebanho bovino de 146.937 animais em 2015 (FAPESPA, 2017), sendo a pecuária a segunda maior atividade econômica e que ainda está em expansão. Devido à praticidade e baixo custo, a pastagem é uma importante opção para o pecuarista, pois se bem manejada, fornece os nutrientes necessários para o bom desempenho animal, garantindo o sucesso e a rentabilidade através da redução do custo de produção e melhor qualidade do produto.

O solo é um recurso natural complexo e de extrema importância para a produção agropecuária, sabe-se que a fertilidade do solo e o seu manejo contribuem para o potencial produtivo da terra. As técnicas agrícolas adotadas propiciam respostas aos atributos dos solos que, por sua vez, podem promover o incremento na fertilidade ou o depauperamento ao longo dos anos, em respostas as práticas de uso e manejo do solo.

O manejo inadequado leva à degradação progressiva do solo resultando não somente no esgotamento da capacidade 
de uso do solo, como também à significativas perdas econômicas na atividade produtiva. Portanto, o diagnóstico da qualidade do solo, é fundamental para a adoção de práticas de manejo que resultem eficientemente, não somente no aumento da produtividade, como também, na conservação do solo e, consequentemente, na sustentabilidade dos sistemas de produção.

O objetivo deste artigo foi avaliar a fertilidade do solo através de parâmetros físico-químicos em áreas de pastagens sob diferentes idades e profundidades, em comparação com a vegetação secundária, no município de Vitória do Xingu, Pará, Brasil.

\section{Metodologia}

O experimento foi realizado no município de Vitória do Xingu - PA, em uma propriedade particular denominada Sítio Babaçulândia, sob as coordenadas geográficas Latitude $2^{\circ} 53^{\prime} 2^{\prime \prime} \mathrm{S}$, Longitude $52^{\circ} 0^{\prime} 17^{\prime \prime} \mathrm{O}$. O clima do município corresponde ao equatorial chuvoso, do tipo Ami, com pequeno período seco, conforme a classificação de Köppen, apresentando temperatura média anual de 26 a $32^{\circ} \mathrm{C}$, umidade relativa do ar de 60 a $95 \%$ e pluviosidade anual de 2013 a $3000 \mathrm{~mm}$ (INMET, 2018). O solo da área estudada é típico das regiões equatoriais, classificado como Latossolo Vermelho Amarelo (PTDRS, 2010).

A pesquisa foi composta por três tratamentos, sendo Tratamento 1 (T1) denominada de vegetação secundária com aproximadamente 30 anos, tendo histórico de uso da área com pastagem e, atualmente, é considerada uma área de preservação; Tratamento 2 (T2) constituída com pastagem com 10 anos; e o Tratamento 3 (T3) com pastagem com 30 anos. A área (T2), apresenta um histórico de área de vegetação secundária com o preparo do solo com derruba e queima, constituída da espécie Panicum maximum cv. Mombaça. A pastagem com 30 anos (T3), é uma área anteriormente com pousio com registros de corte e queima, apresenta histórico de uso da área com atividade cacaueira e, atualmente, é considerada área de pastagem com a implantação da espécie Brachiaria. brizantha cv. Marandu, contudo, a espécie mais predominante na área é o capim do tipo Panicum maximum cv. Mombaça.

As coletas foram realizadas em duas épocas no ano de 2018, em função da maior ou menor intensidade de chuvas na região, sendo a primeira realizada no mês de abril (período chuvoso) e a segunda em setembro (período seco). As amostras deformadas foram coletadas para a determinação das propriedades químicas e da granulometria através do uso de um trado Holandês, de acordo com a metodologia proposta por Santos et al. (2018). As amostras indeformadas para determinação da densidade do solo foram coletadas em anéis cilíndricos de aço inox com volume de $50 \mathrm{~cm}^{3}$, nas profundidades de $0-20 \mathrm{~cm}$, (Embrapa, 2017). Em cada tratamento foram coletadas três amostras simples para formar uma amostra composta. Para cada profundidade e época de coleta, cada tratamento foi composto por duas repetições, totalizando 24 unidades amostrais no experimento. Para T2 durante o período seco não foi possível realizar a coleta das amostras indeformadas, pois o solo não permitia a introdução dos equipamentos de coleta na área e o terreno apresentou resistência aos procedimentos.

As amostras deformadas foram destinadas para a quantificação dos atributos químicos, sendo eles, teores de fósforo $(\mathrm{P})$, potássio $(\mathrm{K})$, enxofre $(\mathrm{S})$, cálcio $(\mathrm{Ca})$, magnésio $(\mathrm{Mg})$, alumínio $(\mathrm{Al})$, acidez potencial $(\mathrm{H}+\mathrm{Al})$, potencial hidrogeniônico $(\mathrm{pH})$, matéria orgânica $(\mathrm{MO})$, ferro $(\mathrm{Fe})$, zinco $(\mathrm{Zn})$, cobre $(\mathrm{Cu})$, manganês $(\mathrm{Mn})$, boro $(\mathrm{B})$, sódio $(\mathrm{Na})$, soma de bases $(\mathrm{SB})$, capacidade de troca catiônica efetiva $\left(\mathrm{CTC}_{\text {efetiva }}\right)$, capacidade de troca catiônica potencial $\left(\mathrm{CTC}_{(\mathrm{pH} 7)}\right)$, saturação por alumínio (m\%) e saturação por bases (V\%). Para interpretação foram utilizados os valores de referência da Embrapa (2009). Os atributos físicos estimados foram densidade do solo (Ds), densidade de partícula (Dp), granulometria e classificação textural, conforme a metodologia descrita por Embrapa (2017).

Para a análise estatística foi utilizado o teste de Wilcoxon $(\mathrm{P}<0,05)$, utilizando o programa Sisvar, realizou-se os testes pelo método não-paramétrico para comparação de duas amostras pareadas. Nesta análise ao invés de considerar apenas o sinal 
das diferenças entre os pares, considera o valor dessas diferenças, ou seja, sendo estabelecido o rank do menor para o maior na análise estatística. Para o teste foram avaliados 27 atributos da análise química do solo. Foram calculados os teores médios de nutrientes do solo para as duas profundidades e nas duas estações climáticas estudadas através da média aritmética, atribuindo valores positivos (+) e negativos (-) para avaliar em quais dos tratamentos os parâmetros químicos apresentaram melhores valores.

\section{Resultados e Discussão}

No período seco, a granulometria franco-arenosa ocorreu em ambas a profundidades. Os solos em todos os tratamentos foram classificados como textura média (Tabela 1). Solos de textura franca, também conhecidos como textura média, definem-se como solo com proporções semelhantes de partículas de areia, silte e argila, o que os torna com boa drenagem e capacidade de retenção de água e índice médio de erodibilidade (Centeno et al., 2017).

Tabela 1. Classificação granulométrica e textural do solo nos tratamentos estudados.

\begin{tabular}{|c|c|c|c|c|}
\hline Tratamentos & \multicolumn{2}{|c|}{ Classificação Granulométrica } & \multicolumn{2}{|c|}{ Classificação Textural } \\
\hline & $0-20 \mathrm{~cm}$ & $20-40 \mathrm{~cm}$ & $0-20 \mathrm{~cm}$ & $20-40 \mathrm{~cm}$ \\
\hline T1 & Franco Arenoso & Franco Siltoso & Média & Média \\
\hline $\mathbf{T} 2$ & Franco Arenoso & Franco Siltoso & Média & Média \\
\hline T3 & Franco Arenoso & Franco Siltoso & Média & Média \\
\hline $\mathbf{T 1}$ & Franco Arenoso & Franco Arenoso & Média & Média \\
\hline $\mathbf{T 2}$ & Franco Arenoso & Franco Arenoso & Média & Média \\
\hline T3 & Franco Arenoso & Franco Arenoso & Média & Média \\
\hline
\end{tabular}

Fonte: Autores (2021).

Na Figura 1, os dados apresentados são referentes a Ds nos tratamentos T1, T2 e T3 para os períodos chuvoso e seco. No período chuvoso, os tratamentos T1, T2 e T3 apresentaram médias de 1,40, 1,53 e 1,56 $\mathrm{g} \mathrm{cm}^{-3}$, respectivamente. Enquanto, no período seco, foram encontrados os valores de Ds nas áreas T1 e T3, de 1,44 e 1,55 g cm ${ }^{-3}$, respectivamente. T1, em comparação com os demais tratamentos, apresentou os menores valores para Ds nos dois períodos climáticos. 
Figura 1. Valores médios de densidade do solo (Ds) nos tratamentos estudados em função do período de coleta.

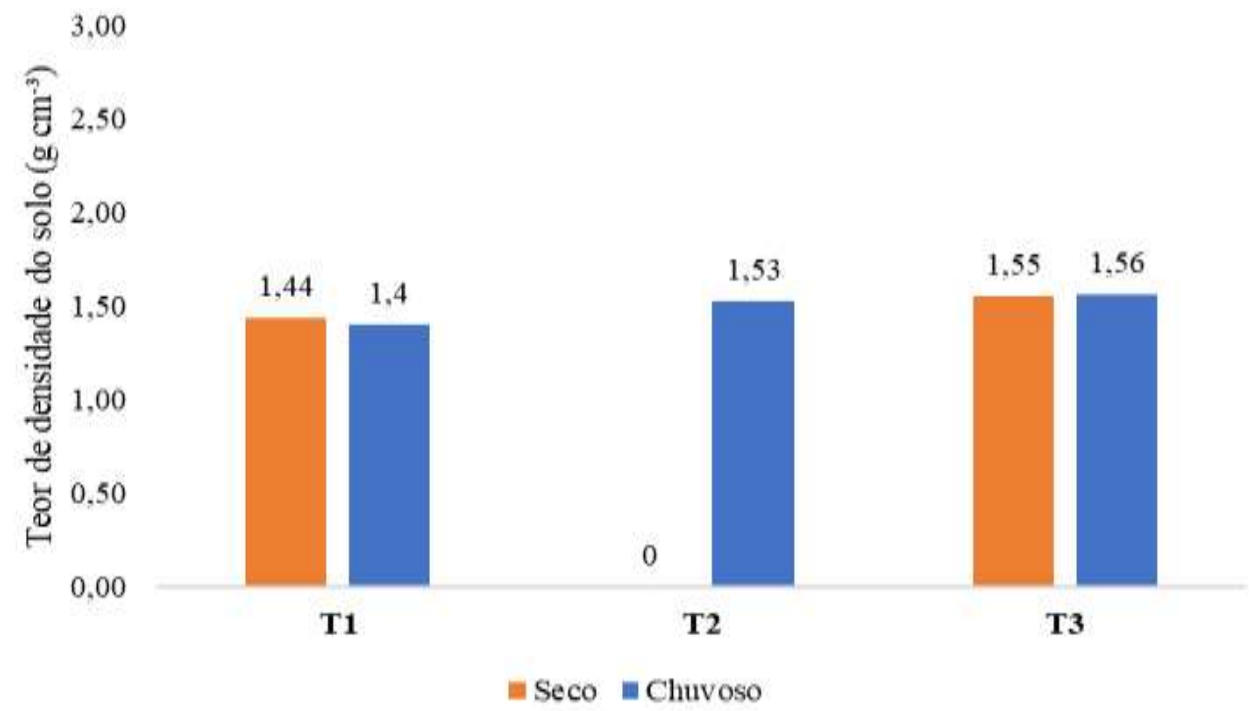

Fonte: Autores (2021).

As áreas T2 e T3 foram as que apresentaram maiores valores de Ds nos períodos. Por se tratar de áreas de pastagens, o pisoteio de animais, bem como outras modalidades de pressão, desencadeiam o processo de compactação. Valores semelhantes foram observados por Valadão Júnior et al. (2017), trabalhando no Latossolo Vermelho Amarelo sob diferentes sistemas de uso do solo, obtiveram valores de $1,55 \mathrm{~g} . \mathrm{cm}^{-3}$ em áreas de pastagem. Esse aumento de densidade pode ser explicado pelo tráfego de máquinas, implementos agrícolas e pisoteio animal principalmente no período de inverno, quando a umidade do solo se encontra elevada, e assim promovendo alta resistência a penetração no período seco. De acordo com Ferreira et al. (2010) e Alves et al. (2015), valores próximos a 1,40 g. $\mathrm{cm}^{-3}$ de Ds podem restringir o desenvolvimento radicular das espécies vegetais.

Figura 2. Valores médios da densidade de partícula (Dp) na profundidade 0-20 cm no período seco.

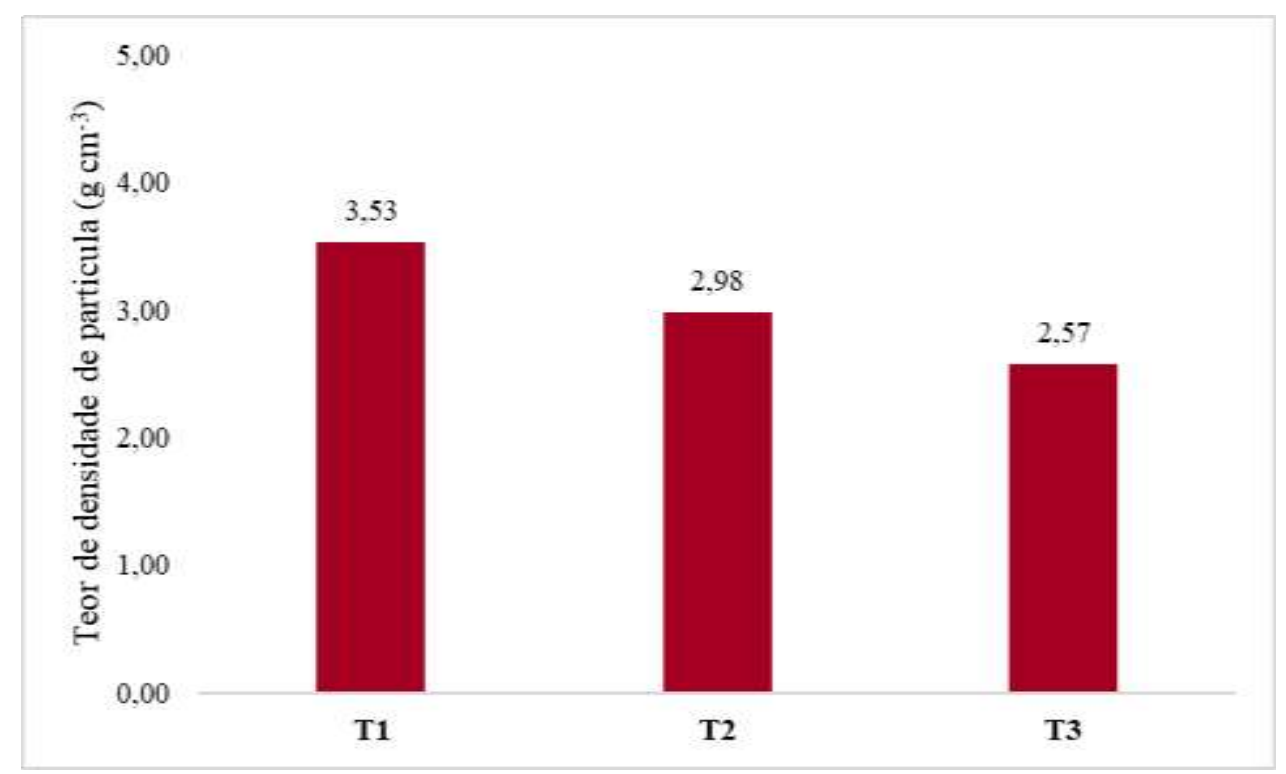

Fonte: Autores (2021). 
Na Figura 2, consta os resultados médios da Dp observada na profundidade de 0-20 cm dentro dos tratamentos T1, T2 e T3 para o período seco. Os tratamentos T1 e T2 apresentaram maiores valores de densidade, 3,53 e 2,98 g.cm ${ }^{-3}$, respectivamente, em comparação ao tratamento T3. A presença de materiais orgânicos sólidos pode diminuir a Dp enquanto a presença de óxidos de ferro e metais pesados pode aumentar o seu valor (Lepsch, 2011). Houve um decréscimo da Dp entre T1 e T3. No processo de compactação do solo, os resíduos superficiais podem atuar na dissipação da energia compactante resultante do pisoteio de animais ou do trânsito de máquinas. A baixa densidade desses resíduos orgânicos, associada com sua susceptibilidade à deformação e elasticidade, torna-os potencialmente capazes de atenuar as cargas aplicadas sobre o solo (Braida et al., 2006).

Na Tabela 2 estão os resultados da análise química do solo para o período chuvoso e seco, sendo observadas as profundidades de 0-20 e 20-40 cm. No período chuvoso, o pH médio variou 5,85 a 6, e no período seco, encontrou-se médias de 5,55 a 5,95, sendo, portanto, classificados com acidez média a fraca. Nesse nível de acidez, ocorre a ausência de Al tóxico (Lepsch, 2011). No período seco, somente T1 e a camada superficial de T3, apresentaram algum nível de toxidez de Al.

A acidez potencial $(\mathrm{H}+\mathrm{Al})$ foi considerada baixa a média em todos os períodos e tratamentos, concentrando-se na camada de 0-20 cm. Em estudos realizados por Silva et al. (2021) apresentou valores para a acidez potencial (H+Al) variando de 3,9 a 8,1 $\mathrm{cmol}_{\mathrm{c}} \cdot \mathrm{dm}^{-3}$, sendo considerada de média a alta para todas as épocas de coleta e profundidades, sob sistemas de manejo com pastagem com e sem mecanização. Para Brady e Weil (2013) a concentração de Al diminui quando os teores de pH estão acima de 5,5, logo, a elevação do pH, ocasiona melhores condições de fertilidade do solo e o melhor desenvolvimento vegetal.

No período chuvoso, em todos os tratamentos, a SB foi considerada média nas duas profundidades, enquanto no período seco foi considerada baixa SB na subsuperfície de T1 e T3. O tratamento T2 apresentou maior CTC (pH 7) e CTC efetiva. Todos os tratamentos apresentaram CTC ( $\mathrm{pH} 7)$ considerada média. No período chuvoso, todos os tratamentos foram classificados com V\% médios, enquanto no período seco, foram considerados baixos. Os teores de MO foram considerados médios.

Os valores dos cátions trocáveis $\mathrm{K}, \mathrm{Ca}, \mathrm{Mg}$ e $\mathrm{Na}$ foram considerados baixos a médios. A diferença entre a CTC potencial e a CTC efetiva, evidencia que a maior parte desses nutrientes está adsorvida nos coloides do solo. Os teores de P encontrados durante o período chuvoso na profundidade $0-20 \mathrm{~cm}$, variou de 3 a $5,5 \mathrm{mg} \mathrm{dm}^{-3}$ para todos os tratamentos. A camada mais profunda do solo apresentou valores de 2 a $2,5 \mathrm{mg} \mathrm{dm}^{-3}$. Diferenças observadas durante o período seco que apresentou com médias de 2 a 4,5 $\mathrm{mg} \mathrm{dm}^{-3}$ na profundidade $0-20 \mathrm{~cm} \mathrm{e} \mathrm{1,5} \mathrm{a} \mathrm{2,5} \mathrm{mg} \mathrm{dm}^{-3}$ na camada subsuperficial.

Oliveira et al. (2017), também obtiveram teores de K, P, Ca e Mg baixos e médios em áreas de pastagens na região Amazônica como encontrados no presente estudo. De acordo com Pereira (2018), no processo derruba e queima, as áreas de pastagens que são estabelecidas em função do aumento da fertilidade do solo ocasionado pelos compostos químicos presentes nas cinzas apresentam ótima produtividade. Contudo, ao passar dos anos observa-se uma redução gradual na produtividade e, consequentemente, baixos teores dos atributos químicos em função do tempo de utilização.

Alves et al. (2017) obtiveram teores de K, P e Ca superiores ao deste estudo em pastagens que receberam a adição de cinzas de biomassa vegetal. Os elementos $\mathrm{Ca}, \mathrm{Mg}$ e S são macronutrientes secundários exigidos em grandes quantidades pelas plantas, devido auxiliarem no crescimento das raízes e dos brotos, eleva a produção de colmos e auxilia na defesa das plantas (Malavolta, 1976). Os nutrientes apresentaram teores médios e baixos respectivamente em todos os tratamentos. 
Tabela 2. Teores médios dos atributos químicos do solo nas áreas de vegetação secundária (T1) e pastagens (T2) e (T3) no período chuvoso e seco.

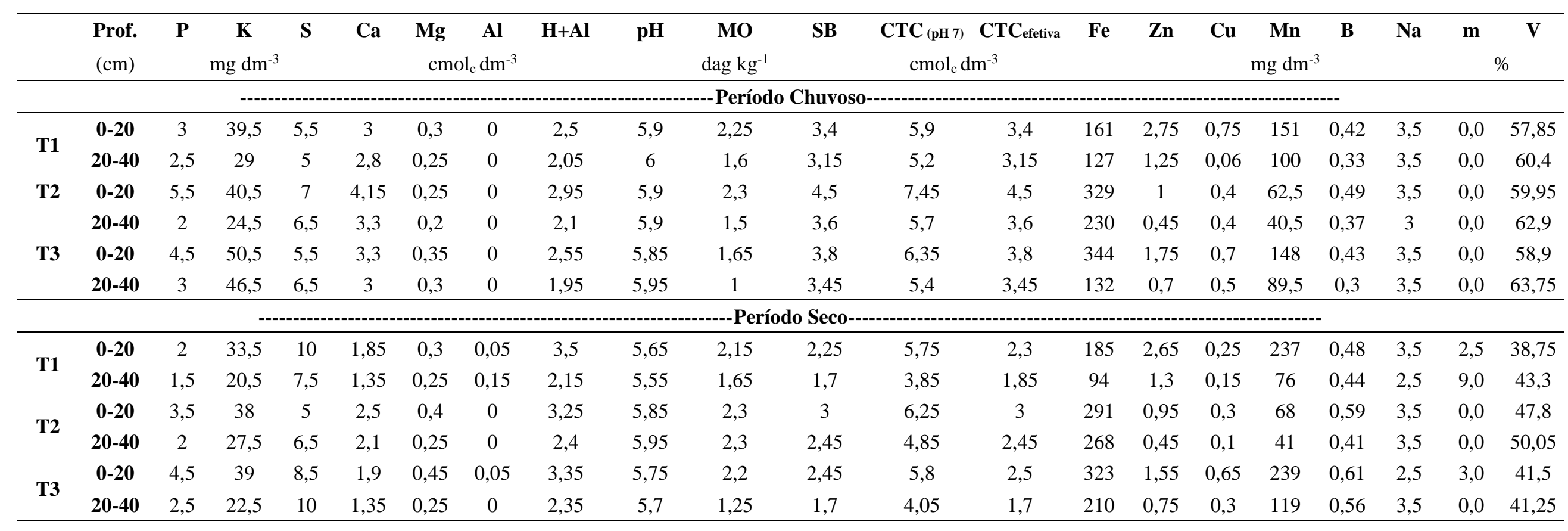

Fonte: Autores (2021). 
Para o $\mathrm{Mg}$ foram obtidos valores referentes de 0,2 a $0,45 \mathrm{cmol}_{\mathrm{c}} \mathrm{dm}^{-3}$, sendo considerados teores muito baixos nos diferentes períodos climáticos. Entre as causas que atuam na explicação dos baixos teores obtidos tanto para Mg como para os outros elementos pertencentes às bases do solo, estão o processo de lixiviação, extração e não reposição destes nutrientes ao longo do tempo (Pereira, 2018). O S apresentou-se com teores médios tanto na vegetação secundária como nas pastagens estudadas. Segundo Brady e Weil (2013), a matéria orgânica é uma das principais fontes naturais de enxofre que podem tornarse disponível aos vegetais.

Maiores teores de MO foram encontrados na profundidade $0-20 \mathrm{~cm}$ para todos os tratamentos no período chuvoso. Estudos realizados por Assis et al. (2021) na região do Pacajá - PA, obteve valores para os teores de matéria orgânica no solo nas profundidades de 0 a $20 \mathrm{~cm}$ de 2,5 dag dm dm $^{-3}$, valores são semelhantes aos encontrados nesta pesquisa. A pastagem de 30 anos (T3) apresentou o menor teor de MO em ambos os períodos climáticos. No período seco, os tratamentos T1 e T3 apresentaram maiores valores desse atributo nas camadas de $0-20 \mathrm{~cm}$, sendo que o único tratamento que não diferiu os valores de MO foi o tratamento T2 que apresentou valores semelhantes para as duas profundidades. Valores inferiores foram obtidos no município de Brasil Novo - PA, para áreas de pastagens de 27 anos e sistema agroflorestal (SAF), aproximadamente 40 anos sob solo podzólico vermelho/amarelo em pastagens com 27 anos 40 anos. Foram encontrados teores entre 0,85 a 0,95 dag $\mathrm{kg}^{-1}$ nas camadas mais profundas do solo, enquanto as camadas superficiais apresentaram médias de 1,65 a $2,1 \mathrm{dag}^{\mathrm{kg}^{-1}}$ (Bezerra et al., 2018).

De acordo com Santos e Salcedo (2010), Salton e Tomazi (2014) e Souza et al. (2018) ratificam que em estudos desenvolvidos em áreas de pastagens, os maiores teores de MO encontram-se nas camadas superficiais do solo, e o acúmulo desse atributo do solo pode ser explicado devido a maior presença de forrageiras. As pastagens desempenham um importante papel na recuperação da fertilidade dos solos, pois auxiliam na manutenção do conteúdo de MO, melhorando a qualidade química e física do solo. A presença do sistema radicular fasciculado de forrageiras, auxilia na formação de agregados no solo e o aumento do conteúdo de $\mathrm{MO}$, resulta em um solo com melhor estrutura e capacidade de retenção de água e nutrientes.

A área de vegetação secundária foi o tratamento que apresentou os valores mais elevados de SB, durante a época seca e sob as diferentes profundidades. Os valores de SB encontrados para as áreas T1, T2 e T3 foram 3,4, 4,5 e 3,8 $\mathrm{cmol}_{\mathrm{c}} \mathrm{dm}^{-3}$, na profundidade 0-20 cm e 3,15, 3,6 e 3,45 $\mathrm{cmol}_{\mathrm{c}} \mathrm{dm}^{-3}$, na profundidade $20-40 \mathrm{~cm}$, no período chuvoso. Para o período seco encontrou-se os valores 2,25, 3,0 e 2,45 $\mathrm{cmol}_{\mathrm{c}} \mathrm{dm}^{-3}$ para a camada superficial e 1,7, 2,45 e 1,7 $\mathrm{cmol}_{\mathrm{c}} \mathrm{dm}^{-3}$, para as camadas mais profundas nos diferentes tratamentos. Foram classificados como valores médios para o período chuvoso, enquanto no período seco, valores médios a baixos.

Segundo Veloso et al. (2007) e Alves et al. (2018), esses resultados de SB são facilmente encontrados na região Amazônica, devido a ocorrência de precipitações elevadas, lixiviação de nutrientes, principalmente de bases trocáveis do solo, seja pela ausência de minerais primários e secundários no solo, responsáveis pela reposição dessas bases que são lixiviadas, consequentemente, gera baixos índices de saturação por bases e alta saturação por Al.

Para a V\% durante o período chuvoso, nos tratamentos estudados, os valores foram maiores que 50\%, caracterizandoos como solos eutrófico. Para o período seco, observou-se teores de V\% menores que 50\% nos tratamentos T1 e T3, sendo considerados solos distróficos, ou seja, apresentam baixa fertilidade, influenciando no aporte nutricional da vegetação. Para o m\%, observou-se que durante o período seco apenas os tratamentos T1 e T3 apresentaram os médios de 2,5 a 9\%, sendo considerados teores baixos.

Teores médios de Fe foram encontrados em T1 e teores elevados em T2 e T3, nos diferentes períodos climáticos. Para todos os tratamentos, o $\mathrm{Zn} \mathrm{e} \mathrm{Cu}$, apresentaram valores muito baixos a baixos nos diferentes períodos climáticos, enquanto para o B e Mn, foram considerados médios a muito alto. Segundo Brady e Weil (2013) o pH do solo afeta a solubilidade de quase todos os nutrientes, mas essa influência é mais predominante sobre o Fe, Mn, Zn e Mo. Esses teores elevados dos atributos 
químicos nas pastagens estão associados à ausência da utilização de prática de calagem e reposição das espécies forrageiras na região (Bezerra et al., 2019).

Na Tabela 3, consta os resultados do teste de Wilcoxon $(P<0,05)$ entre tratamentos na mesma profundidade e no mesmo período. No período chuvoso, todos os tratamentos apresentaram diferenças significativas na camada de $0-20 \mathrm{~cm}$, evidenciando que nas áreas estudadas, os atributos analisados diferem substancialmente. Na camada 20-40 cm no mesmo período, somente o contraste T1 X T3 rejeitou a hipótese nula. No período seco, a comparação T1 X T2, na camada de 0-20 $\mathrm{cm}$, apresentou diferenças altamente significativas. As diferenças são mais críticas entre os tratamentos quando em condições mais úmidas.

Tabela 3. Teste de Wilcoxon entre tratamentos na mesma profundidade e no mesmo período.

\begin{tabular}{|c|c|c|c|c|c|c|c|}
\hline \multicolumn{8}{|c|}{ Período-Chuvoso (PC) } \\
\hline $\begin{array}{l}\text { Prof. } \\
\text { (cm) }\end{array}$ & & & & $\mathbf{S}$ & $\operatorname{Pr} \geq S$ & & \\
\hline \multirow{3}{*}{$0-20$} & $\mathrm{~T} 1$ & $\mathrm{X}$ & $\mathrm{T} 2$ & -69 & 0,0212 & $*$ & Rejeita $\mathrm{Ho}$ \\
\hline & $\mathrm{T} 1$ & $\mathrm{X}$ & $\mathrm{T} 3$ & -70 & 0,0297 & $*$ & Rejeita Ho \\
\hline & $\mathrm{T} 2$ & $\mathrm{X}$ & $\mathrm{T} 3$ & 71 & 0,0396 & $*$ & Rejeita Ho \\
\hline \multirow{3}{*}{$20-40$} & $\mathrm{~T} 1$ & $\mathrm{X}$ & $\mathrm{T} 2$ & -43 & 0,2551 & NS & Aceita Ho \\
\hline & $\mathrm{T} 1$ & $\mathrm{X}$ & $\mathrm{T} 3$ & $-78,5$ & 0,0213 & $*$ & Rejeita Ho \\
\hline & $\mathrm{T} 2$ & $\mathrm{X}$ & $\mathrm{T} 3$ & 10 & 0,7817 & NS & Aceita Ho \\
\hline \multicolumn{8}{|c|}{ Período-Seco (PS) } \\
\hline $\begin{array}{l}\text { Prof. } \\
\text { (cm) }\end{array}$ & & & & $\mathbf{S}$ & $\operatorname{Pr} \geq S$ & & \\
\hline \multirow{3}{*}{$0-20$} & $\mathrm{~T} 1$ & $\mathrm{X}$ & $\mathrm{T} 2$ & $-93,5$ & 0,0088 & $* *$ & Rejeita Ho \\
\hline & $\mathrm{T} 1$ & $\mathrm{X}$ & $\mathrm{T} 3$ & -32 & 0,4271 & NS & Aceita Ho \\
\hline & $\mathrm{T} 2$ & $\mathrm{X}$ & $\mathrm{T} 3$ & 51 & 0,2269 & NS & Aceita Ho \\
\hline \multirow{3}{*}{$20-40$} & $\mathrm{~T} 1$ & $\mathrm{X}$ & $\mathrm{T} 2$ & -66 & 0,094 & NS & Aceita Ho \\
\hline & $\mathrm{T} 1$ & $\mathrm{X}$ & $\mathrm{T} 3$ & 27 & 0,4236 & NS & Aceita Ho \\
\hline & $\mathrm{T} 2$ & $\mathrm{X}$ & $\mathrm{T} 3$ & 54 & 0,1013 & NS & Aceita Ho \\
\hline
\end{tabular}

* significativo; ** altamente significativo; NS não significativo; $\mathrm{S}$ significância do $\operatorname{Rank} \operatorname{Pr} \geq \mathrm{S}$.

Fonte: Autores (2021).

A compactação superficial, ocasionada pelo pastejo de animais, assim como o conteúdo de matéria orgânica em razão da maior atividade microbiana, devido ao aporte de material vegetal, fazem com que a camada superficial do solo em sistemas pastoris seja mais sensível às mudanças de manejo (Lisbôa et al., 2016). O Teste de Wilcoxon entre os diferentes períodos (Tabela 4) identificou que houve diferenças altamente significativas na camada 0-20 cm em T1 e, diferenças significativas na camada 20-40 cm de T3. A vegetação secundária apresentou maior fertilidade durante o período chuvoso e em comparação aos demais tratamentos. Nas camadas superficiais de solos mais arenosos, a presença de matéria orgânica é um importante fator para a agregação do solo e na redução da lixiviação de nutrientes. Em T3, houve um decréscimo dos valores médios dos atributos químicos na camada subsuperficial no período seco. 
Tabela 4. Teste de Wilcoxon entre diferentes períodos climáticos nas profundidades 0-20 e 20-40 cm.

\begin{tabular}{|c|c|c|c|c|c|c|}
\hline \multicolumn{7}{|c|}{ PS vs PC $(0-20 \mathrm{~cm})$} \\
\hline T1 PS & $\mathrm{x}$ & $\mathrm{T} 1 \mathrm{PC}$ & $-91,5$ & 0,006 & $* *$ & Rejeita Ho \\
\hline T2 PS & $\mathrm{x}$ & $\mathrm{T} 2 \mathrm{PC}$ & -51 & 0,984 & NS & Aceita Ho \\
\hline T3 PS & $\mathrm{x}$ & T3 PC & -30 & 0,4307 & NS & Aceita Ho \\
\hline \multicolumn{7}{|c|}{ PS vs PC (20-40 cm) } \\
\hline T1 PS & $\mathrm{x}$ & $\mathrm{T} 1 \mathrm{PC}$ & -41 & 0,3068 & NS & Aceita Ho \\
\hline T2 PS & $\mathrm{x}$ & $\mathrm{T} 2 \mathrm{PC}$ & $-44,5$ & 0,1527 & NS & Aceita Ho \\
\hline T3 PS & $\mathrm{x}$ & T3 PC & -86 & 0,0106 & $*$ & Rejeita Ho \\
\hline \multicolumn{7}{|c|}{ 0-20 PS vs 20-40 PS } \\
\hline $\mathrm{T} 1$ & $\mathrm{x}$ & $\mathrm{T} 1$ & -24 & 0,5525 & NS & Aceita Ho \\
\hline $\mathrm{T} 2$ & $\mathrm{x}$ & $\mathrm{T} 2$ & $-37,5$ & 0,263 & NS & Aceita Ho \\
\hline $\mathrm{T} 3$ & $\mathrm{x}$ & T3 & -18 & 0,6737 & NS & Aceita Ho \\
\hline \multicolumn{7}{|c|}{ 0-20 PC vs 20-40 PC } \\
\hline $\mathrm{T} 1$ & $\mathrm{x}$ & $\mathrm{T} 1$ & $-35,5$ & 0,3205 & NS & Aceita Ho \\
\hline $\mathrm{T} 2$ & $\mathrm{x}$ & $\mathrm{T} 2$ & $-27,5$ & 0,4148 & NS & Aceita Ho \\
\hline T3 & $\mathrm{x}$ & T3 & $-64,5$ & 0,0638 & NS & Aceita Ho \\
\hline
\end{tabular}

* significativo; ** altamente significativo; NS não significativo.

Fonte: Autores (2021)

\section{Considerações Finais}

As áreas de pastagens com 10 (T2) e 30 anos (T3), apresentaram maiores teores de nutrientes em comparação a vegetação secundária (T1). No entanto, os resultados de densidade do solo e de partícula, sugerem maior estágio de degradação em T3 e T2, quando comparado com T1.

Tais resultados sugerem que, apesar de melhores condições químicas em áreas de pastagens em função do manejo nutricional das culturas forrageiras, nestas áreas, as condições físicas podem levar, progressivamente, a processos de degradação e consequente esgotamento do solo. O manejo da fertilidade do solo em áreas compactadas resulta na lixiviação dos nutrientes, levando a perdas econômicas e nutritivas. Medidas voltadas para a recuperação das pastagens, a fim de contribuir no potencial produtivo, bem como, estratégias de manejo, são requeridas na propriedade, tendo como principais efeitos ganhos produtivos o maior retorno econômico e a redução dos impactos ambientais.

\section{Referências}

Alves, A. R., Nascimento, P. S. O., Lima, W. G., Viana, S. S., \& Ribon, A. A. (2015). Influência do manejo na densidade relativa de um latossolo amarelo sob diferentes usos e manejo de pastagem e mata nativa. Anais do II Congresso de ensino, pesquisa e extensão da UEG. Pirenópolis, GO, 2.

Alves, M. H. D., Silva, K. W. dos S., Corrêa, J. S., Texeira, O. M. M., \& Sousa, J. P. M. (2018). Levantamento comparativo de propriedades químicas do solo com diferentes culturas em Santa Isabel do Pará, Pará. Cadernos de Agroecologia, 13 (2), 1-7.

Alves, M. V, Nesi, C. N, Naibo, G, Spricigo, J. G, Bender, A. C, Cruz, D. C. A, Chagas, A. \& Curti, G. L. (2017). Comportamento químico do solo e satisfação dos produtores rurais após o uso de cinza. Scientia Agraria, 18 (1), 76-82.

Assis, J. M. de, Silva, S. A. S. da, Lisboa, S. C. de L., Farias, V. D. da S., Nogueira, A. da S., \& Santos, M. A. S. dos. (2021). Atributos físicos, químicos e biológicos do solo sob influência do feijão guandu (Cajanus cajan (L.) Millsp.) no município de Pacajá, Pará, Brasil. In: Rendin, E. (Org.). Ciências Rurais em Foco. 2(6), 40-61, Poisson.

Bezerra, C. B., Souza, A. J.J., Corrêa, M. M., Lima, J. R. de S., Santoro, K. R., Souza, E. S., \& Oliveira, C. L. (2019). Latossolo húmico sob pastagem com diferentes intensidades de usos: atributos químicos e físico-hídricos. Revista Brasileira de Ciências Agrárias, 14 (1), 1-9.

Bezerra, D. A, Silva, S. A. S, Silva, R. M, Alves, P. H. C. dos S, \& Moraes, R. B. (2018). Avaliação dos atributos químicos do solo em sistemas agroflorestais e pastagem, no município de Brasil Novo - Pará. Agrarian Academy, 5 (9), 83-93.

Brady, N. C., \& Weil, R. R. (2013) Elementos da natureza e propriedades dos solos. (3a ed.), Buokman. 
Braida, J. A., Reichert, J. M., Veiga, M. D., \& Reinert, D. J. (2006). Resíduos vegetais na superfície e carbono orgânico do solo e suas relações com a densidade máxima obtida no ensaio Proctor. Revista Brasileira de Ciência do Solo, 30(4), 605-614.

Centeno, L. N., Guevara, M. D. F., Cecconello, S. T., Sousa, R. O., \& Timm, L. C. (2017). Textura do solo: Conceitos e aplicações em solos arenosos. Revista Brasileira de Engenharia e Sustentabilidade, 4 (1), 31-37.

Dias, L. C. P., Pimenta, F. M., Santos, A. B., Costa, M. H., \& Ladle, R. J. (2016). Patterns of land use, extensification, and intensification of Brazilian agriculture. Global Change Biology, 22 (8), 2887-2903.

Dias-Filho, M. B. (2019). Recuperação de pastagens degradadas na Amazônia. Embrapa.

Domingues, M. S, Bermann, C. (2012). O arco de desflorestamento na Amazônia: da pecuária à soja. Ambiente \& sociedade, 15 (2), 1-22.

EMBRAPA - Empresa Brasileira de Pesquisa Agropecuária. (2009). Manual de análises químicas de solos, plantas e fertilizantes (2a ed). Embrapa.

EMBRAPA - Empresa Brasileira de Pesquisa Agropecuária. (2017). Manual de métodos de análise de solo (3a ed). Embrapa.

FAPESPA - Fundação Amazônia de Amparo a Estudos de Pesquisa. (2017). Anuário estatístico do Pará. 〈http://www.fapespa.pa.gov.br >.

Ferreira, R. R. M., Tavares Filho, J., \& Ferreira, V. M. (2010). Efeitos de sistemas de manejo de pastagens nas propriedades físicas do solo. Semina: Ciências Agrárias, 31(4), 913-932.

INMET - Instituto Nacional de Meteorologia. (2018). Município de Vitória do Xingu - PA. <http://www.inmet.gov.br/portal/>.

Lepsch, I. F. (2011). 19 Lições de pedologia. Oficina de Texto.

Lisbôa, F. M., Donagemma, G. K., Burak, D. L., Passos, R. R., \& Mendonça, E. D. S. (2016). Indicadores de qualidade de Latossolo relacionados à degradação de pastagens. Pesquisa agropecuária brasileira, 51(9), 1184-1193.

Malavolta, E. (1976). Manual de química agrícola: nutrição de plantas e fertilizantes do solo. Editora Agronômica Ceres.

Oliveira, A. N., Oliveira, A. N., Silva, K. R., Silva, L. J. D. A., Mello, A. H. (2017). Atributos químicos de solo sob diferentes sistemas de uso e manejo no Projeto de Assentamento Veneza - São Domingos do Araguaia, PA. Revista Agroecossistemas, 9 (1), 170-179.

Pereira, G. E dos S., Locatelli, M., \& Silva Filho, E. P. (2018). A atividade humana como fator de substituição da floresta nativa por diferentes tipos de cobertura vegetal influenciando os aspectos de fertilidade do solo na região de Ariquemes, RO. Anais do X Seminário Temático da Rede Internacional CASLACEPIAL: Conhecimentos Etnocientíficos e Territorialidades Alternativas.

PTDRS - Plano Territorial de Desenvolvimento Rural Sustentável (2010). Território da Cidadania Transamazônica Estado do Pará. Altamira: FVPP. http://sit.mda.gov.br/download/ptdrs/ptdrs_qua_territorio095.pdf>.

Salton, J. C., \& Tomazi, M. (2014). Sistema radicular de plantas e qualidade do solo: comunicado técnico (6a ed). Dourados: Embrapa Agropecuária Oeste.

Santos, A. C., \& Salcedo, I. H. (2010). Relevo e fertilidade do solo em diferentes estratos da cobertura vegetal na bacia hidrográfica da represa Vaca Brava, Areia, PB. Revista Árvore, 34 (2), 277-285.

Santos, H. G., Jacomine, P. K. T., Anjos, L. H. C., Oliveira, V. A., Lumbreras, J. F., Coelho, M. R., Almeida, J. A. de, Araujo Filho, J. C. de, Oliveira, J. B. de, \& Cunha, T. J. F. (2018). Sistema brasileiro de classificação de solos (5a ed). Embrapa.

Silva, E. R., Silva, S. A. S. da, Lisboa, S. C. de L., Farias, V. D. da S., Hamid, S. S., Santos, M. A. S. dos. (2021). Atributos físicos e químicos do solo sob diferentes sistemas de manejo em uma unidade de produção rural no município de Pacajá, Pará, Brasil. In: Silva-Matos, R. R. S. da, Machado, N. A. F., Cordeiro, K. V. (Orgs.). Sistemas de produção nas ciências agrárias. 2(3),25-38. Atena.

Souza, W. R, Silva, S. A. S, Silva, R. M., Alves, R. de F, \& Silva, J. R (2018). Atributos físico-químicos do solo em uma voçoroca no município de Brasil Novo - Pará: um estudo de caso. Rev. Tree Dimensional, ProFloresta, 3(5), 14-26.

Valadão Júnior, D. D, Valadão, F. C. de A., \& Silva, G. J. (2017). Atributos físicos e Matéria Orgânica de um Latossolo sob diferentes manejos. Cultura Agronômica: Revista de Ciências Agronômicas, 26 (3), 237-250.

Veloso, C. A. C., Botelho, S. M., \& Rodrigues, J. E. L. F. (2007). Correção da acidez do solo. In: Cravo, M. S.; Viégas, I. J. M.; Brasil, E. C. (Eds). Recomendações de adubação e calagem para o estado do Pará. Embrapa Amazônia Oriental. 